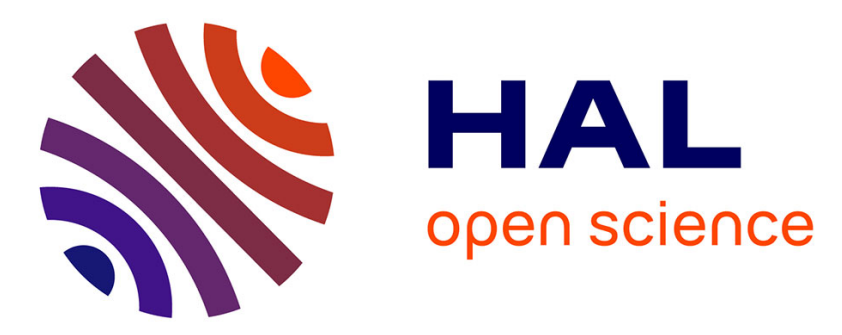

\title{
Numerical modeling of carbon distribution and precipitation during directional solidification of photovoltaic silicon
}

Carmen Stelian

\section{- To cite this version: \\ Carmen Stelian. Numerical modeling of carbon distribution and precipitation during directional solid- ification of photovoltaic silicon. International Journal of Heat and Mass Transfer, 2019, 145, pp.118775 -. 10.1016/j.ijheatmasstransfer.2019.118775 . hal-03487327}

\section{HAL Id: hal-03487327 \\ https://hal.science/hal-03487327}

Submitted on 21 Dec 2021

HAL is a multi-disciplinary open access archive for the deposit and dissemination of scientific research documents, whether they are published or not. The documents may come from teaching and research institutions in France or abroad, or from public or private research centers.
L'archive ouverte pluridisciplinaire HAL, est destinée au dépôt et à la diffusion de documents scientifiques de niveau recherche, publiés ou non, émanant des établissements d'enseignement et de recherche français ou étrangers, des laboratoires publics ou privés.

\section{(ㄷ)(1) $\$$}

Distributed under a Creative Commons Attribution - NonCommerciall 4.0 International 
Numerical modeling of carbon distribution and precipitation during directional solidification of photovoltaic silicon

\author{
Carmen Stelian
}

Univ. Grenoble Alpes, CNRS, Grenoble INP, SIMAP-EPM, 1340 Rue de la Piscine, BP 75, F-38402 Saint Martin d'Hères, France

Corresponding author: steliancarmen@yahoo.com

\begin{abstract}
Numerical modeling is used to investigate carbon distribution and precipitation in directional solidification of multicrystalline silicon. Computations are performed for samples of $6 \mathrm{~cm}$ in diameter grown in a Vertical Bridgman Freezing (VGF) system starting from silicon feedstock with different grades of contamination in carbon. The value of the unknown reaction rate coefficient governing the carbon precipitation in the silicon melt was estimated in the present work by comparing the numerically computed concentration profiles to the experimental results taken from the literature. Numerical results show that the growth rate has a significant influence on the interface deflection, melt convection and carbon precipitation. It is found that the silicon samples grown from the melts of low carbon contamination $\left(<10^{18} \mathrm{at} / \mathrm{cm}^{3}\right)$ exhibit low content in $\mathrm{SiC}$ precipitates, even if they are solidified at high growth rates $(1-2 \mathrm{~cm} / \mathrm{h})$. The samples with high initial carbon contamination $(5$. $\left.10^{18} \mathrm{at} / \mathrm{cm}^{3}\right)$ should be solidified at much lower rates $(0.2 \mathrm{~cm} / \mathrm{h})$ in order to avoid the formation of $\mathrm{SiC}$ precipitates.
\end{abstract}


Keywords: Directional solidification; Semiconducting silicon; Computer simulation; Impurities; Carbon transport and precipitation

\section{Introduction}

Directional solidification has become the leading technique for growing the multicrystalline silicon (mc-Si) for photovoltaic applications. The solar cells efficiency depends on the structural quality and the impurity content of the silicon material. The contamination with carbon $(\mathrm{C})$, nitrogen $(\mathrm{N})$ and oxygen $(\mathrm{O})$ is very deleterious, reducing the conversion efficiency of the solar cells. Carbon and nitrogen can form precipitates $\left(\mathrm{SiC}\right.$ and $\left.\mathrm{Si}_{3} \mathrm{~N}_{4}\right)$, when their concentration exceeds a critical solubility limit in the molten silicon. Silicon carbide $(\mathrm{SiC})$ precipitates are undesirable because they allow the formation of small grains and also cause ohmic shunts, which reduce the solar cells performance. Many studies have been dedicated to the analysis of the impurities distribution in directional solidification of multicrystalline silicon [1-13]. Some experiments and numerical modeling were conducted to investigate $\mathrm{C}, \mathrm{N}$ and $\mathrm{O}$ distribution in mc-Si ingots of $6 \mathrm{~cm}$ diameter solidified at different rates by using the vertical gradient freezing (VGF) method [5-7]. The axial and radial distribution of impurities were measured in samples resulting from silicon feedstock with different grades of contamination. The modeling of species transport performed in [6] considers the solute segregation at the crystal-melt interface, the incorporation of impurities at the melt-gas interface and the particles precipitation during the solidification process. Simulations are conducted at different values of some unknown physical parameters, such as the reaction rate coefficient governing the particles precipitation, or the mass transfer coefficient which describes the impurities incorporation from the gas in the melt. 
The values of the reaction rate coefficient $(\alpha)$, governing the carbon precipitation in silicon melts, differ significantly in the literature. Numerical computations performed in [4] show that the carbon distribution in the silicon samples remains practically unchanged when the reaction rate coefficient increases beyond a critical value $\left(\alpha=100 s^{-1}\right)$. Simulations carried out in [8] by using the reaction rate coefficients given by the existing literature failed to get reasonable results for $\mathrm{SiC}$ distribution in the silicon ingots. Further investigations performed in this work have shown the best agreement between modeling and experimental observations is obtained in the case of much lower values of the reaction rate coefficient ( $\alpha=10^{-4} s^{-1}$ ) than predicted in the literature.

In the present paper, numerical modeling is applied to investigate the distribution and precipitation of carbon during directional growth of multicrystalline silicon. The simulation results are compared to experimental measurements performed in [5-7], in order to estimate some unknown parameters describing the carbon distribution and precipitation in the molten silicon.

\section{Physical model}

The modeling is performed for the experimental growth of silicon by using the VGF technique [5-7]. Silicon ingots of $6 \mathrm{~cm}$ diameter and $4 \mathrm{~cm}$ length were grown in open fused silica crucibles at different growth rates: $0.2 \mathrm{~cm} / \mathrm{h}, 1 \mathrm{~cm} / \mathrm{h}$ and $2.2 \mathrm{~cm} / \mathrm{h}$. After crystallization, the axial and radial distribution of impurities ( $\mathrm{C}$ and $\mathrm{N}$ ) was measured by FTIR-spectroscopy.

The present simulations use the finite element code COMSOL Multiphysics to solve the heat transfer, momentum and species equations (Eq. 1-3) for an axisymmetric domain containing the silicon sample and the crucible (see Fig. 1): 


$$
\begin{gathered}
\rho \mathrm{c}_{\mathrm{P}}\left(\frac{\partial \mathrm{T}}{\partial \mathrm{t}}+\overrightarrow{\mathrm{u}} \cdot \nabla \mathrm{T}\right)=\mathrm{k} \nabla^{2} \mathrm{~T} \\
\rho\left[\frac{\partial \overrightarrow{\mathrm{u}}}{\partial \mathrm{t}}+(\overrightarrow{\mathrm{u}} \cdot \nabla) \overrightarrow{\mathrm{u}}\right]=-\nabla \mathrm{p}+\mu \nabla^{2} \overrightarrow{\mathrm{u}}+\rho \overrightarrow{\mathrm{g}}\left[1-\beta_{\mathrm{T}}\left(\mathrm{T}-\mathrm{T}_{0}\right)\right] \\
\frac{\partial \mathrm{C}}{\partial \mathrm{t}}+\overrightarrow{\mathrm{u}} \cdot \nabla \mathrm{C}=\mathrm{D} \nabla^{2} \mathrm{C}+\mathrm{R}
\end{gathered}
$$

In the above equations, $\rho, c_{p}, k, p, \mu, \beta_{T}, D, R, T, C, \vec{u}$ and $\vec{g}$ denote the density, specific heat, thermal conductivity, pressure, dynamic viscosity, thermal expansion coefficient, diffusion coefficient, reaction rate, temperature, concentration, flow velocity and the gravity vector. The values of the physical parameters used in the simulation are: $\rho_{S, L}=2580 \mathrm{~kg} / \mathrm{m}^{3}, \rho_{C}=3290 \mathrm{~kg} / \mathrm{m}^{3}, k_{S}=$ $22 \mathrm{~W} / \mathrm{m} \cdot \mathrm{K}, k_{L}=64 \mathrm{~W} / \mathrm{m} \cdot \mathrm{K}, \quad k_{C}=30 \mathrm{~W} / \mathrm{m} \cdot \mathrm{K}, \quad c_{p, S L}=1040 \mathrm{~J} / \mathrm{kg} \cdot \mathrm{K}, c_{p, C}=710 \mathrm{~J} / \mathrm{kg} \cdot \mathrm{K}$, $\mu=0.75 \cdot 10^{-3} \mathrm{~kg} / \mathrm{m} \cdot \mathrm{s}, \beta_{T}=7 \cdot 10^{-5} \mathrm{~K}^{-1}(\mathrm{~S}, \mathrm{~L}$ and $\mathrm{C}$ denote the solid, the liquid and the crucible).

The reaction rate in Eq. 3 describes the impurities precipitation, and is given by:

$$
\mathrm{R}=-\alpha\left(\mathrm{C}-\mathrm{C}_{\mathrm{P}}\right)
$$

where $\alpha$ is the reaction rate coefficient and $C_{P}$ is the solubility limit of impurities in the silicon melt. The coefficient $\alpha$ is actually unknown and will be estimated in the following paragraph. The precipitation occurs when the impurities concentration is greater than the solubility limit. Therefore, the reaction rate is negative when $C>C_{P}$ and vanishes when $C<C_{P}$. The solubility limit of carbon $C_{P}=14 \cdot 10^{17} \mathrm{at} / \mathrm{cm}^{3}$ (at the melting temperature of silicon $T_{S}=1685$ ) was carried out from the Si-C phase diagram given in [4].

Thermal boundary conditions are imposed at the crucible wall according to the experimental conditions described in [5-7]. A linear temperature profile characterized by a constant vertical gradient $G_{T}=2 \mathrm{~K} / \mathrm{cm}$ (as specified in [6]) was imposed at the external wall of the crucible. The 
temperatures at the top and the bottom surfaces of the sample are equilibrated with the crucible wall temperature at the same vertical location. During the solidification process, the external temperature is lowered at cooling rates which are adjusted in order to obtain the solidification rates used in experiments $(0.2 \mathrm{~cm} / \mathrm{h}, 1 \mathrm{~cm} / \mathrm{h}$ and $2.2 \mathrm{~cm} / \mathrm{h})$.

The no-slip boundary condition $(\vec{u}=0)$ is imposed at the solid walls of the liquid domain, and the normal velocity is set to zero $\left(u_{n}=0\right)$ at the melt-gas interface.

The boundary conditions for species transport are imposed as follows:

- No flux condition at the crucible walls:

$$
\Phi=-\mathrm{D} \cdot \nabla \mathrm{C} \cdot \vec{n}=0
$$

- Mass flux conservation at the solid-liquid interface:

$$
\mathrm{D} \cdot \nabla \mathrm{C} \cdot \overrightarrow{\mathrm{n}}=(1-\mathrm{K}) \cdot(\vec{V} \cdot \vec{n}) \cdot \mathrm{C}_{\mathrm{I}}
$$

where $K$ is the segregation coefficient, $V$ is the interface velocity, $\vec{n}$ is the normal vector and $C_{I}$ is the solute concentration in the liquid at the interface.

- Mass flux across the melt-gas interface:

$$
\Phi=\mathrm{h}\left(\mathrm{C}-\mathrm{C}_{\mathrm{ref}}\right)
$$

where $h$ is the mass transfer coefficient and $C_{r e f}$ is the reference solute concentration in the gas near the free surface of the melt. These parameters are unknown and will be estimated in the following paragraph by comparing the numerical results with the experimental data. This boundary condition describes the carbon incorporation at the top surface of the melt via $\mathrm{CO}$ gas from the atmosphere. Eq. (7) is similar to the Noyes-Whitney equation which relates the dissolution rate of solids in a liquid solvent. The reference concentration is dependent on the temperature $C_{r e f} \sim \exp (-\Delta G / R \cdot T)$. In our case the reaction energy $\Delta G$ is much higher than the $R \cdot T$ term ( $R$ is the ideal gas constant), so the 
variation of $C_{r e f}$ with the temperature during the solidification process was neglected in the present computations.

The Heat Transfer, Laminar Flow and Deformed Geometry modules of COMSOL Multiphysics are used in the present work. Numerical computations are performed in two steps. Steady-state simulations are performed firstly in order to compute the temperature and flow fields in the samplecrucible system. Then, transient computations of temperatures, flow velocities and species distribution are started with the initial conditions carried out from the steady-state computations. The transient computations use a deformable mesh technique to compute the shape of the solid-liquid interface. The structured mesh contains 5000 triangular elements with higher density of nodes near the solid-liquid interface. The minimum element size is $0.03 \mathrm{~cm}$.

\section{Simulation results}

\subsection{Thermal field and convection}

Simulations of temperature and velocity fields are performed for three growth rates used in experiments: $0.2 \mathrm{~cm} / \mathrm{h}, 1 \mathrm{~cm} / \mathrm{h}$ (standard growth rate of $\mathrm{mc}-\mathrm{Si}$ ingots) and $2.2 \mathrm{~cm} / \mathrm{h}$. Experimental visualization of the solidification front has shown a significant increase of the interface deflection $(f)$ as the growth rate increases: $f_{\text {exp }}=0.4 \mathrm{~cm}$ at $V=0.2 \mathrm{~cm} / \mathrm{h}, f_{\text {exp }}=0.78 \mathrm{~cm}$ at $V=1 \mathrm{~cm} / \mathrm{h}$ and $f_{\text {exp }}=1.3 \mathrm{~cm}$ at $V=2.2 \mathrm{~cm} / \mathrm{h}$ [5-7]. This is explained by the amount of the latent heat released at the solid-liquid interface, which is directly dependent on the solidification rate [14].

Fig. 1 shows the temperature and velocity fields computed in the case of VGF experiments conducted at different growth rates. The computed values of the interface deflection at the middle stage of the growth process (solidified fraction $f_{S}=0.5$ ) are in good agreement with the experimental results: $f_{\text {num }}=0.37 \mathrm{~cm}$ at $V=0.2 \mathrm{~cm} / \mathrm{h}, f_{\text {num }}=0.7 \mathrm{~cm}$ at $V=1 \mathrm{~cm} / \mathrm{h}$ and $f_{\text {num }}=1.25 \mathrm{~cm}$ at $V=$ 
$2.2 \mathrm{~cm} / \mathrm{h}$. The interface deflection is changing during the growth process because of coupled thermalbuoyancy flow effects. Changes in interface shape during DSS crystallization of large silicon ingots have been also observed in other simulation works [7,15].

At the beginning of the solidification process, the buoyancy driven convection is characterized by two opposite vortices (case no shown on the figure). The primary vortex, which is located near the solidliquid interface, has the maximum velocity $u_{\max } \approx 10^{-3} \mathrm{~m} / \mathrm{s}$. In this region, the fluid circulates in a clockwise direction, influencing the solute distribution near the solidification front. The secondary vortex is located near the top surface of the melt and has a low magnitude. The flow pattern is changing during the solidification process. At the middle stage of the growth process (case shown in Fig. 1) the secondary vortex disappears and the primary vortex becomes tangent to the melt-gas interface. In the case of high growth rate $(V=2.2 \mathrm{~cm} / \mathrm{h})$ the flow is reversed, with the fluid rising along the crucible walls (Fig. 1c). The change in the flow pattern is explained in Fig. 2. The figure shows the evolution of temperature and velocity fields at the middle stage of the growth process $\left(f_{S} \geq\right.$ 0.5). The blue line represents the solidification isotherm. At the solidification time $t=6000 \mathrm{~s}$, the clockwise flow becomes tangent at the free surface of the melt. The intense flow homogenizes the temperatures in the melt, so the temperatures at the upper surface of the melt are close to the solidification point. Then, the clockwise convection vanishes and the liquid at the top of melt is undercooled $(t=6600 \mathrm{~s})$. However, the crystallization is not likely to start from the free surface of the melt, since the undercooling is very low $\left(\Delta T_{\text {undercooling }}=0.1 \mathrm{~K}\right)$. The image plotted at $t=$ $6700 \mathrm{~s}$ shows a reversed flow generated by a small negative vertical temperature gradient $\left(G_{T}=\right.$ $0.1 \mathrm{~K} / \mathrm{cm})$ 
Fig. 3 compares the values of the interface deflection carried out from numerical modeling, experiments [5] and by applying the analytical formula proposed in [14]:

$$
\mathrm{f}=\frac{\mathrm{d}}{4}\left[\left(\frac{\mathrm{k}_{\mathrm{L}}}{\mathrm{k}_{\mathrm{S}}} \cdot \frac{\mathrm{k}_{\mathrm{S}} \mathrm{S}_{\mathrm{S}}+\mathrm{k}_{\mathrm{C}} \mathrm{S}_{\mathrm{C}}}{\mathrm{k}_{\mathrm{L}} \mathrm{S}_{\mathrm{S}}+\mathrm{k}_{\mathrm{C}} \mathrm{S}_{\mathrm{C}}}-1\right)+\frac{\mathrm{k}_{\mathrm{C}} \mathrm{S}_{\mathrm{C}}}{\mathrm{k}_{\mathrm{S}} \mathrm{S}_{\mathrm{S}}+\mathrm{k}_{\mathrm{C}} \mathrm{S}_{\mathrm{C}}} \cdot \frac{\mathrm{VH}}{\mathrm{k}_{\mathrm{L}} \mathrm{G}_{\mathrm{L}}-\mathrm{VH}}\right]
$$

In the above equation, $d, S, G_{L}$ and $H$ denote the sample diameter, sample (or crucible) surface, vertical temperature gradient in the liquid and the latent heat of the solidification. Eq. 8 predicts a significant increase of the interface curvature with increasing growth rate, which is in agreement with the numerical and experimental results.

\subsection{Carbon distribution}

\subsubsection{Low concentration feedstock}

Simulations are performed for the crystallization experiment started from a feedstock having a low concentration of carbon $C_{0}=7 \cdot 10^{17} \mathrm{at} / \mathrm{cm}^{3}$ [5-7]. The sample is solidified at $V=1 \mathrm{~cm} / \mathrm{h}$ in an open crucible. The initial concentration of carbon in the melt is below to the solubility limit $\left(C_{P}=\right.$ $14 \cdot 10^{17} \mathrm{at} / \mathrm{cm}^{3}$ ), so a low precipitation rate is expected in this experiment. The carbon distribution should be not much affected by the SiC particle formation, therefore the simulation can be used to estimate the diffusion coefficient $D$ and the mass transfer coefficient $h$.

The experimental carbon distribution along the symmetry axis [6] is compared to the numerical results obtained with different values of the diffusion coefficient in Fig. 4. The precipitation and carbon incorporation at the top surface of the melt are neglected in these simulations $(\alpha=0, h=0)$. The values of the diffusion coefficient are varied between $0.5 \cdot 10^{-8} \mathrm{~m}^{2} / \mathrm{s}$ (curve A) and 3.5 . $10^{-8} \mathrm{~m}^{2} / \mathrm{s}$ (curve C). One can observe that the value given in literature $D=3.5 \cdot 10^{-8} \mathrm{~m}^{2} / \mathrm{s}$ [16] is too high (see curve C). A better agreement between simulation and experiment is obtained at smaller diffusion coefficient $D=1.5 \cdot 10^{-8} \mathrm{~m}^{2} / \mathrm{s}$ (curve B). 
The influence of precipitation rate on carbon distribution is shown in Fig. 5. Simulations are performed with different values of the reaction rate coefficient: $\alpha=0$ (curve A), $\alpha=1.2 \cdot 10^{-4} s^{-1}$ (curve B) and $\alpha=50 \cdot 10^{-4} s^{-1}$ (curve C). The incorporation of carbon at the top surface of the melt is neglected $(h=0)$ and the diffusion coefficient is $D=1.5 \cdot 10^{-8} \mathrm{~m}^{2} / \mathrm{s}$. Concentration profiles obtained without and respectively with precipitation (curves A and B) are almost identical, indicating a small amount of $\mathrm{SiC}$ precipitates resulting in this experiment. By increasing the reaction rate coefficient to $\alpha=50 \cdot 10^{-4} S^{-1}$, the carbon concentration is almost constant for a solidified fraction $f_{S}>0.5$, which is in disagreement with the experimental data. The profile computed with $\alpha=1.2$. $10^{-4} S^{-1}$ (curve B) is close to the experimental results. Some differences are observed for the last solidified part of the ingot, were the numerical results are not well fitting the experimental profile. This can be explained by accounting the differences between the experimental and the numerically computed solidification rate. The measurements performed over the complete solidification process have shown significant variations of the growth rate by the end of the crystallization process $\left(f_{S}>\right.$ 0.7) [5]. Random variations of the growth rate during the solidification process cannot be included in the present numerical model. Therefore, we expect some differences between the measured and numerically computed concentration profiles.

The value of the reaction rate coefficient $\alpha=1.2 \cdot 10^{-4} S^{-1}$ (profile B in Fig. 5) was estimated by using the measured concentration profile in the experiment started from the high concentration feedstock $\left(C_{0}=57 \cdot 10^{17} \mathrm{at} / \mathrm{cm}^{3}\right)$, since in the case the carbon concentration is more sensitive to the precipitation rate (see Fig. 7). Several computations were performed by varying the values of the reaction rate coefficient in the range $10^{-5} s^{-1}<\alpha<100 s^{-1}$. The best agreement was obtained for $\alpha=1.2 \cdot 10^{-4} s^{-1}$ (curve B in Fig. 7). 
The carbon incorporation at the melt-gas interface is analyzed in Fig. 6. The mass transfer coefficient is varied in the range $0 \leq h \leq 0.1 \mathrm{~m} / \mathrm{s}$. The concentration $C_{r e f}$ of carbon (or $\mathrm{CO}$ ) in the gas is actually unknown in the experiments. The values of $C_{r e f}$ are varied between the solubility limit $C_{P}=$ $14 \cdot 10^{17} \mathrm{at} / \mathrm{cm}^{3}$ and $17 \cdot 10^{17} \mathrm{at} / \mathrm{cm}^{3}$. Surprising, the better agreement between the experiment and simulation is obtained for the case which neglects the carbon incorporation at the top surface of the melt (curve A). The computations performed by varying the mass transfer coefficient in the range $10^{-4} \mathrm{~m} / \mathrm{s} \leq h \leq 0.1 \mathrm{~m} / \mathrm{s}$ at the same reference concentration, show no changes in the carbon concentration profiles. On the other hand, the profiles computed by increasing the reference concentration from $C_{r e f}=14 \cdot 10^{17} \mathrm{at} / \mathrm{cm}^{3}$ (curve B) to $C_{r e f}=17 \cdot 10^{17} \mathrm{at} / \mathrm{cm}^{3}$ (curve C) exhibit higher carbon concentrations than measured in the experiments.

Concluding these simulations, we observe a good agreement between experiments and simulations at lower values of some physical parameters (as the diffusion coefficient $D=1.5 \cdot 10^{-8} \mathrm{~m}^{2} / \mathrm{s}$ and the reaction rate coefficient $\alpha \cong 10^{-4} s^{-1}$ ), than those used in other numerical works [4-7]. It seems also that the amount of carbon incorporated at the melt-gas interface during the solidification process is negligible. This could be explained by the low CO content of the gas atmosphere in VGF experiments described in [5-7].

\subsubsection{High concentration feedstock}

In this paragraph, the simulations are performed for two solidification experiments $(V=0.2 \mathrm{~cm} / \mathrm{h}$ and $V=1 \mathrm{~cm} / \mathrm{h})$ started from high contaminated silicon melts $\left(C_{0}=57 \cdot 10^{17} \mathrm{at} / \mathrm{cm}^{3}\right)[5-7]$. In this case, the initial concentration of carbon is much higher than the solubility limit $\left(C_{P}=14\right.$. 
$10^{17} \mathrm{at} / \mathrm{cm}^{3}$ ), therefore a massive $\mathrm{SiC}$ particle precipitation in the melt is expected. The present simulations are conducted in order to adjust the value of the reaction rate coefficient $\alpha$.

The first set of computations are carried out for the solidification experiment at $V=1 \mathrm{~cm} / \mathrm{h}$ (interface deflection $f=0.7 \mathrm{~cm}$ ). The axial carbon distribution computed at different values of $\alpha$ is compared to the experimental data from [5] in the Fig. 7. The experimental results show a significant increase of carbon concentration at the beginning of the growth process $\left(f_{S}<0.3\right)$, then a plateau with small oscillations $\left(0.3<f_{S}<0.6\right)$, and, finally, an ascendant concentration profile at the end of the growth process $\left(f_{S}>0.6\right)$. The best agreement between modeling and experiment has been obtained for $\alpha=1.2 \cdot 10^{-4} s^{-1}$ (curve B). The axial concentration increases rapidly during the first stage of the growth process $\left(f_{S}<0.3\right)$, due to the segregation phenomenon at the crystal-melt interface. The segregation coefficient of carbon in the silicon melt is very small $(K=0.07)$, so a large amount of carbon is rejected at the interface during the crystallization process. Moreover, the solute transported by the flow from the crucible walls to the sample center, enhances the content of carbon in this region. Starting with a critical value of the concentration, the excess of carbon at the crystal-melt interface is converted in SiC precipitates. This could explain the solute plateau obtained for $0.3<f_{S}<0.6$. By the end of the solidification process $\left(f_{S}>0.6\right)$, the flow cell is located near the crucible wall. The poor convective mixing at the sample center causes an increasing axial concentration, as shown by the simulation and experiment. The simulation performed without the reaction rate, shows a continuously increasing concentration profile (curve A). The large area between the curves A and B, which is proportional to the carbon consumed in reaction, suggests a significant amount of $\mathrm{SiC}$ precipitates resulting in this experiment. The profile $\mathrm{C}$ in Fig. 7 was obtained by a small increase of the reaction coefficient to $\alpha=2.5 \cdot 10^{-4} s^{-1}$. The results show a significant decrease of the carbon concentration 
over the solidified fraction $f_{S}=0.2$, which is in disagreement with the experiment. We conclude that the numerical results are now more sensitive to small variations of $\alpha$ values.

The results shown in Fig. 8 are used to compute the radial segregation in the solidified sample, by applying the formula:

$$
\delta C=\frac{C_{\max }-C_{\min }}{C_{a v}}
$$

$C_{\max }, C_{\min }$ and $C_{a v}$ are respectively, the maximum, minimum and the average concentration in the solid sample at a given solidified fraction. The experimental measurements performed in [5] have shown a high radial segregation $\delta C=0.6$ at the solidified fraction $f_{S}=0.45(2 \mathrm{~cm}$ height from the ingot bottom). The maximum concentration is reached at the sample center and the minimum near the crucible wall. Fig. 8 shows the axial (ingot's center) and the lateral (ingot's periphery) carbon distribution, plotted for the cases computed without precipitation $(\alpha=0)$ and with precipitation $(\alpha=$ $1.2 \cdot 10^{-4} s^{-1}$ ). The radial segregation is computed by using the profiles $\mathrm{B}$ and $\mathrm{D}$, obtained from the simulations with the reaction rate. The value $\delta C=0.66$ obtained at the solidified fraction $f_{S}=0.45$ is in good agreement with the experimental one.

The area between the curves computed with and without precipitation is proportional to the content of SiC precipitates in the solidified ingot. The area between curves A-B is larger than C-D area, showing an accumulation of $\mathrm{SiC}$ precipitates at the sample center over the solidified fraction $f_{S}=0.3$. This is in agreement with IR-transmission images of the vertical cut at the ingot center shown in [7].

The second set of simulations are performed in the case of the crystallization experiment conducted at $V=0.2 \mathrm{~cm} / \mathrm{h}$ growth rate (initial concentration in the melt $C_{0}=57 \cdot 10^{17} \mathrm{at} / \mathrm{cm}^{3}$ ). The numerical computations show different results in this case. The interface deflection is smaller as compared with 
the previous case: $f \approx 0.4 \mathrm{~cm}$. The flow pattern is similar to the previous case, with a maximum velocity $u_{\max } \approx 0.6 \cdot 10^{-3} \mathrm{~m} / \mathrm{s}$. The transient simulation shows no reversed flow in the primary vortex by the end of the growth, so the convection is more stable during the solidification process. The fluid rises at the sample center and downwards along the crucible wall.

Fig. 9 illustrates the comparison of the axial carbon concentration measured in experiment [5] to the simulation results (curves A and B). The physical parameters estimated in the previous paragraph are used in this simulation: $D=1.5 \cdot 10^{-8} \mathrm{~m}^{2} / \mathrm{s}, \alpha=1.2 \cdot 10^{-4} \mathrm{~s}^{-1}$ and $h=0$ (curve B). The profile A is computed by neglecting the precipitation $(\alpha=0)$. Numerical results, in agreement with the experimental data, show an almost constant concentration profile along the sample axis. At this low growth rate $(V=0.2 \mathrm{~cm} / \mathrm{h})$, the amount of carbon rejected at the solid-liquid interface is much smaller than for the previous case $(V=1 \mathrm{~cm} / \mathrm{h})$, therefore an equilibrium is established between carbon segregation and precipitation. The area between curves A and B shows a less content of SiC precipitates in the solidified sample, but not negligible.

\section{Conclusions}

Numerical modeling of carbon distribution in silicon samples has been compared to the experimental results from [5-7], in order to estimate some unknown physical parameters which characterize the diffusion and the precipitation rate of the impurities in the silicon melt.

Carbon distribution in the samples is analyzed for two sets of experiments started from silicon melts with different grades of contamination. Good agreements between the simulations and experiments 
are obtained at smaller values of the diffusion coefficient $\left(D=1.5 \cdot 10^{-8} \mathrm{~m}^{2} / \mathrm{s}\right)$ than those used in other simulation works. The analysis of carbon precipitation shows much lower values of the reaction rate coefficient than expected $\left(1 s^{-1}<\alpha<100 s^{-1}\right.$ in other simulation works). Numerical results are in agreement with the measured concentration profiles for computations performed with $\alpha=1.2$. $10^{-4} s^{-1}$. This result is in agreement with the estimations given in [8].

The modeling of the experiment started from a low concentration feedstock $\left(C_{0}=7 \cdot 10^{17} \mathrm{at} / \mathrm{cm}^{3}\right)$ shows that the reaction rate is low, resulting in a low content of $\mathrm{SiC}$ precipitates in the ingot, even at high growth rates $(V \geq 1 \mathrm{~cm} / \mathrm{h})$. At high grades of contamination with carbon $\left(C_{0}=57\right.$. $10^{17} \mathrm{at} / \mathrm{cm}^{3}$ ), massive precipitation takes place, especially at growth rates $V \geq 1 \mathrm{~cm} / \mathrm{h}$. The analysis of the carbon incorporation at the melt-gas interface shows a negligible mass flux through this boundary in the VGF experiments described in [5-7].

Finally, we conclude that the formation of $\mathrm{SiC}$ precipitates can be avoided if the initial content of carbon in the silicon melt is below the solubility limit $\left(\approx 10^{18} \mathrm{at} / \mathrm{cm}^{3}\right)$. Samples can be grown at high growth rates $V \geq 1 \mathrm{~cm} / \mathrm{h}$, without forced convection, since the carbon precipitation rate increases only at the end of the growth process.

\section{Acknowledgments}

CS acknowledges the Grenoble Institute of Technology for supporting this work in the frame of the International Mobility Program. Prof. T. Duffar, Prof. Y. Delannoy and Miguel Kamguem from SIMAP-EPM Institute of Grenoble are gratefully acknowledged for their help. 


\section{References}

[1] A. Muhlbauer, V. Diers, A. Walther, Removal of $\mathrm{C} / \mathrm{Si}$ from liquid silicon by directional solidification, Journal of Crystal Growth 108 (1991) 41-52.

[2] P.J. Ribeyron, F. Durand, Oxygen and carbon transfer during solidification of semiconductor grade silicon in different processes, Journal of Crystal Growth 210 (2000) 541-553.

[3] N. Mangelinck-Noel, T. Duffar, Modelling of the transition from planar faceted front to equiaxed growth: application to photovoltaic polycrystalline silicon, Journal of Crystal Growth 311 (2008) 2025 .

[4] L. Liu, S. Nakano, K. Kakimoto, Carbon concentration and particle precipitation during directional solidification of multicrystalline silicon for solar cells, Journal of Crystal Growth 310 (2008) 2192-2197.

[5] M. Trempa, C. Reimann, J. Friedrich, G. Muller, The influence of growth rate on formation and avoidance of $\mathrm{C}$ and $\mathrm{N}$ related precipitates during directional solidification of multicrystalline silicon, Journal of Crystal Growth 312 (2010) 1517-1524.

[6] C. Reimann, M. Trempa, T. Jung, J. Friedrich, G. Muller, Modeling of incorporation of O, N, C and formation of related precipitates during directional solidification of silicon under consideration of variable processing parameters, Journal of Crystal Growth 312 (2010) 878-885.

[7] C. Reimann, M.Trempa, J. Friedrich, G. Muller, About the formation and avoidance of C and N related precipitates during directional solidification of multi-crystalline silicon from contaminated feedstock, Journal of Crystal Growth 312 (2010) 1510-1516.

[8] A. N. Vorob'ev, A.P. Sid'ko, V.V. Kalaev, Advanced chemical model for analysis of Cz and DS Si-crystal growth, Journal of Crystal Growth 386 (2014) 226-234.

[9] B. Gao, X.J. Chen, S. Nakano, K. Kakimoto, Crystal growth of high-purity multicrystalline silicon using a unidirectional solidification furnace for solar cells, Journal of Crystal Growth 312 (2010) $1572-1576$ 
[10] Y.Y. Teng, J.C. Chen, C. W. Lu, C.Y. Chen, The carbon distribution in multicrystalline silicon ingots grown using the directional solidification process, Journal of Crystal Growth 312 (2010) 12821290.

[11] J.P. Garandet, N. Kaupp, D. Pelletier, Y. Delannoy, Solute segregation in a lid driven cavity: Effect of the flow on the boundary layer thickness and solute segregation, Journal of Crystal Growth 340 (2012) 149-155.

[13] L. Liu, W. Ma, X. Qi, Z. Li, Y. Zhang, Global simulation of coupled oxygen and carbon transport in an industrial directional solidification furnace for crystalline silicon ingots: effect of crucible coating, International Journal of Heat and Mass Transfer 108 (2017) 2355-2364.

[14] C. Stelian, T. Duffar, J.L. Santailler, F. Barvinschi, I. Nicoara, Analysis of the factors affecting the interface deflection in the vertical Bridgman configuration, Crystal Research and Technology 36 (7) (2001) 663-673.

[15] W. Ma, G. Zhong, L. Sun, Q. Yu, X. Huang, L. Liu, Influence of an insulation partition on a seeded directional solidification process for quasi-single crystalline silicon ingot for high-efficiency solar cells, Solar Energy Materials \& Solar Cells 100 (2012) 231-238.

[16] T. A. Engh, C.J. Simensen, Principles of Metal Refining, Oxford University Press, 1993. 
Figure captions

Figure 1: Temperature field and isotherms (left side) and velocity field (right side) computed at different growth rates: (a) $V=0.2 \mathrm{~cm} / \mathrm{h}\left(f_{\text {num }}=0.37 \mathrm{~cm}\right)$; (b) $V=1 \mathrm{~cm} / \mathrm{h}\left(f_{\text {num }}=0.7 \mathrm{~cm}\right)$; (c) $V=2.2 \mathrm{~cm} / \mathrm{h}\left(f_{\text {num }}=1.25 \mathrm{~cm}\right)$.

Figure 2: Evolution of temperature field and isotherms (left side) and velocity field at the middle stage of the growth process $\left(f_{S} \geq 0.5\right)$ for the experiment conducted at high pull rate $(V=2.2 \mathrm{~cm} / \mathrm{h})$.The blue line represents the solidification isotherm.

Figure 3: Interface deflection versus the growth rate. The results are carried out from experiments [5] (blue squares), simulation (green diamonds) and Eq. 8 (red line).

Figure 4: Comparison of measured carbon distribution along the center axis (square symbols from [6]) to numerical results obtained with different values of the diffusion coefficient: $D=0.5 \cdot 10^{-8} \mathrm{~m}^{2} / \mathrm{s}$ (curve A), $D=1.5 \cdot 10^{-8} \mathrm{~m}^{2} / \mathrm{s}$ (curve B) and $D=3.5 \cdot 10^{-8} \mathrm{~m}^{2} / \mathrm{s}$ (curve C). Growth rate $V=$ $1 \mathrm{~cm} / \mathrm{h}$, initial concentration $C_{0}=7 \cdot 10^{17} \mathrm{at} / \mathrm{cm}^{3}$.

Figure 5: Comparison of measured carbon distribution along the center axis (square symbols from [6]) to numerical results obtained with different values of the reaction rate coefficient: $\alpha=0$ (curve A), $\alpha=1.2 \cdot 10^{-4} \mathrm{~s}^{-1}$ (curve B) and $\alpha=50 \cdot 10^{-4} \mathrm{~s}^{-1}$ (curve C). Growth rate $V=1 \mathrm{~cm} / \mathrm{h}$, initial concentration $C_{0}=7 \cdot 10^{17} \mathrm{at} / \mathrm{cm}^{3}$, diffusion coefficient $D=1.5 \cdot 10^{-8} \mathrm{~m}^{2} / \mathrm{s}$.

Figure 6: Comparison of measured carbon distribution along the center axis (square symbols from [6]) 
to numerical results obtained with different values of the mass transfer coefficient and the reference concentration: $h=0$ (curve A), $h=0.001 \mathrm{~m} / \mathrm{s}$ and $C_{\text {ref }}=14 \cdot 10^{17} \mathrm{at} / \mathrm{cm}^{3}$ (curve B), $h=$ $0.001 \mathrm{~m} / \mathrm{s}$ and $C_{r e f}=17 \cdot 10^{17} \mathrm{at} / \mathrm{cm}^{3}$ (curve C). Growth rate $V=1 \mathrm{~cm} / \mathrm{h}$, initial concentration $C_{0}=7 \cdot 10^{17} \mathrm{at} / \mathrm{cm}^{3}$, diffusion coefficient $D=1.5 \cdot 10^{-8} \mathrm{~m}^{2} / \mathrm{s}$, reaction rate coefficient $\alpha=1.2$. $10^{-4} s^{-1}$

Figure 7: Comparison of measured carbon distribution along the center axis (square symbols from [5]) to numerical results obtained with different values of the reaction rate coefficient: $\alpha=0$ (curve A), $\alpha=1.2 \cdot 10^{-4} s^{-1}$ (curve B) and $\alpha=2.5 \cdot 10^{-4} s^{-1}$ (curve C). Growth rate $V=1 \mathrm{~cm} / \mathrm{h}$, initial concentration $C_{0}=57 \cdot 10^{17} \mathrm{at} / \mathrm{cm}^{3}$, diffusion coefficient $D=1.5 \cdot 10^{-8} \mathrm{~m}^{2} / \mathrm{s}$.

Figure 8: Carbon distribution on the longitudinal direction: axial distribution for $\alpha=0$ (curve A) and $\alpha=1.2 \cdot 10^{-4} s^{-1}$ (curve B), lateral distribution for $\alpha=0$ (curve C) and $\alpha=1.2 \cdot 10^{-4} s^{-1}$ (curve D). Growth rate $V=1 \mathrm{~cm} / \mathrm{h}$, initial concentration $C_{0}=57 \cdot 10^{17} \mathrm{at} / \mathrm{cm}^{3}$, diffusion coefficient $D=$ $1.5 \cdot 10^{-8} \mathrm{~m}^{2} / \mathrm{s}$

Figure 9: Comparison of measured carbon distribution along the center axis (square symbols from [5]) to numerical results obtained for: $\alpha=0$ (curve A) and $\alpha=1.2 \cdot 10^{-4} s^{-1}$ (curve B). Growth rate $V=0.2 \mathrm{~cm} / \mathrm{h}, \quad$ initial concentration $C_{0}=57 \cdot 10^{17} \mathrm{at} / \mathrm{cm}^{3}$, diffusion coefficient $D=1.5$. $10^{-8} \mathrm{~m}^{2} / \mathrm{s}$ 


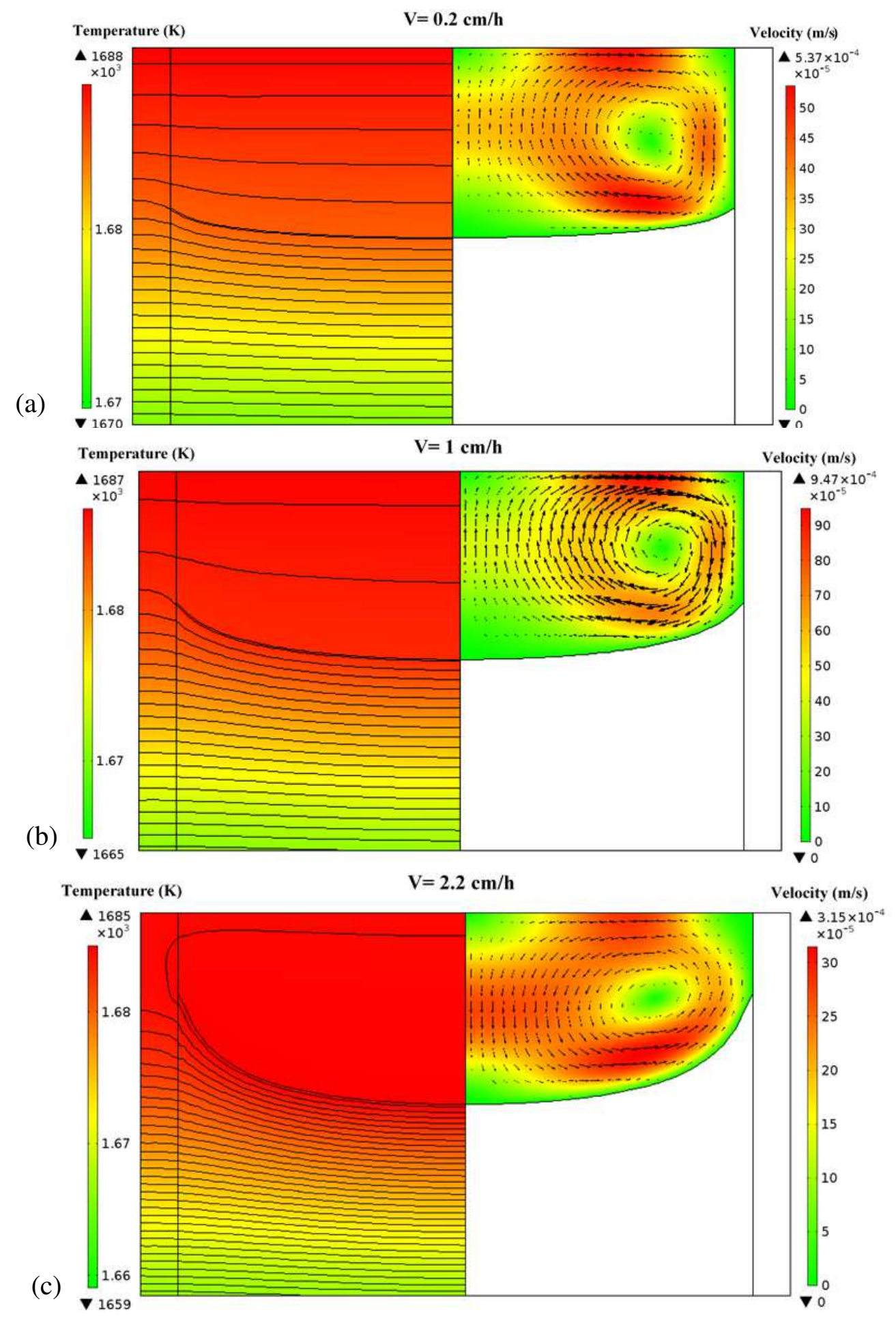

Fig. 1. Temperature field and isotherms (left side) and velocity field (right side) computed at different growth rates: (a) $V=0.2 \mathrm{~cm} / \mathrm{h}\left(f_{\text {num }}=0.37 \mathrm{~cm}\right)$; (b) $V=1 \mathrm{~cm} / \mathrm{h}\left(f_{\text {num }}=0.7 \mathrm{~cm}\right) ;$ (c) $V=$ $2.2 \mathrm{~cm} / \mathrm{h}\left(f_{\text {num }}=1.25 \mathrm{~cm}\right)$. 


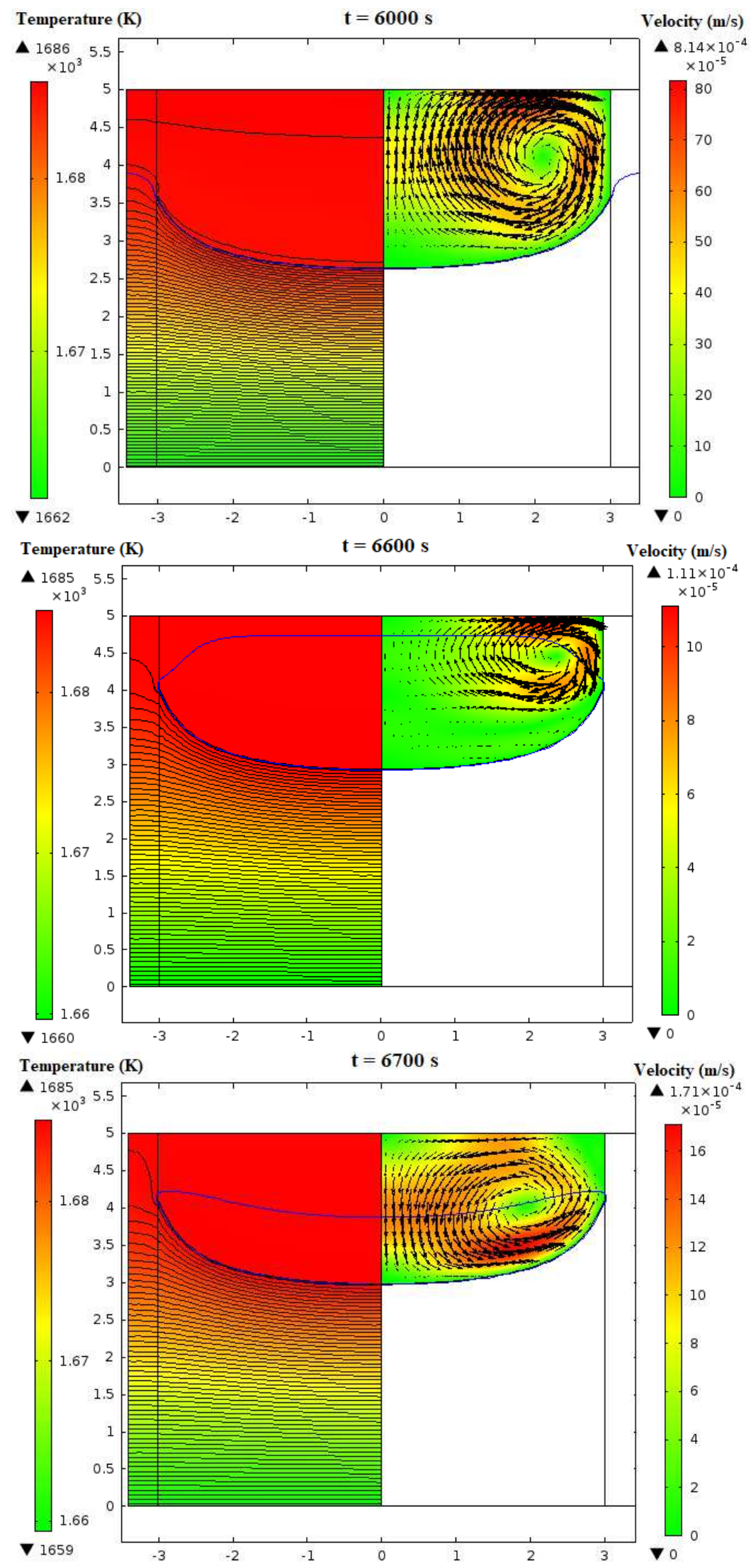

Fig. 2. Evolution of temperature field and isotherms (left side) and velocity field at the middle stage of the growth process $\left(f_{S} \geq 0.5\right)$ for the experiment conducted at high pull rate $(V=2.2 \mathrm{~cm} / \mathrm{h})$. The blue line represents the solidification isotherm. 


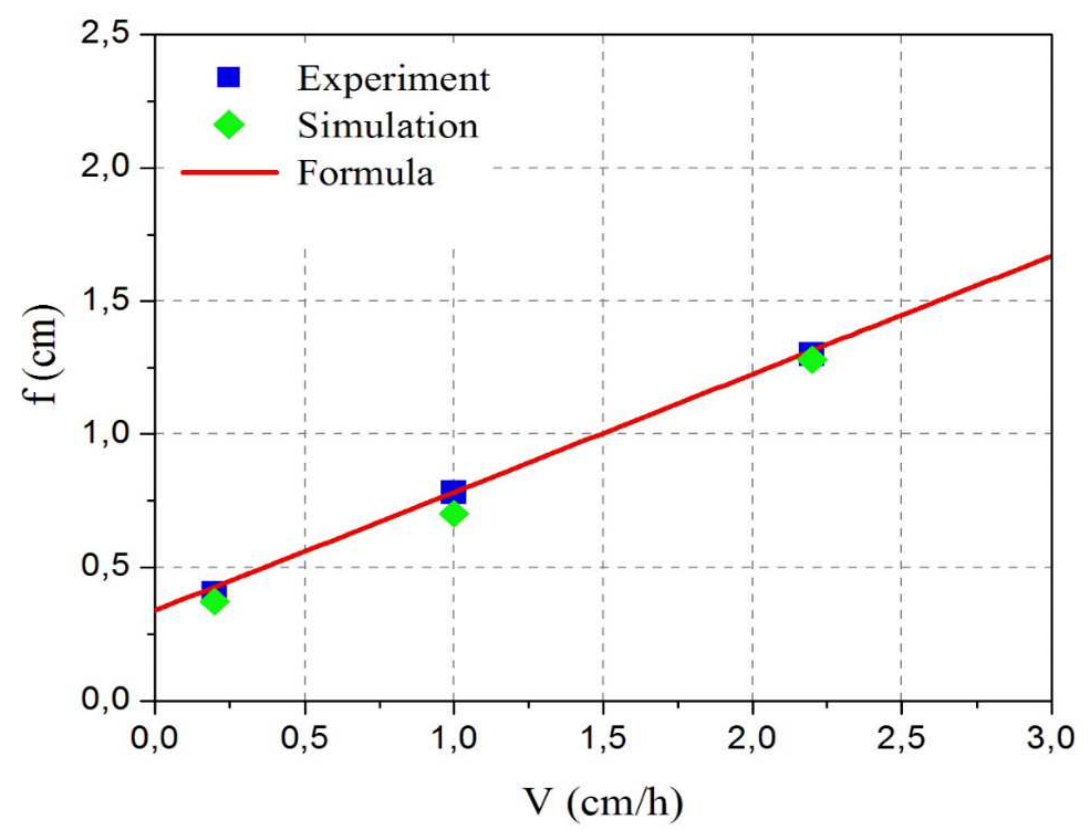

Fig. 3. Interface deflection versus the growth rate. The results are carried out from experiments [5] (blue squares), simulation (green diamonds) and Eq. 8 (red line). 


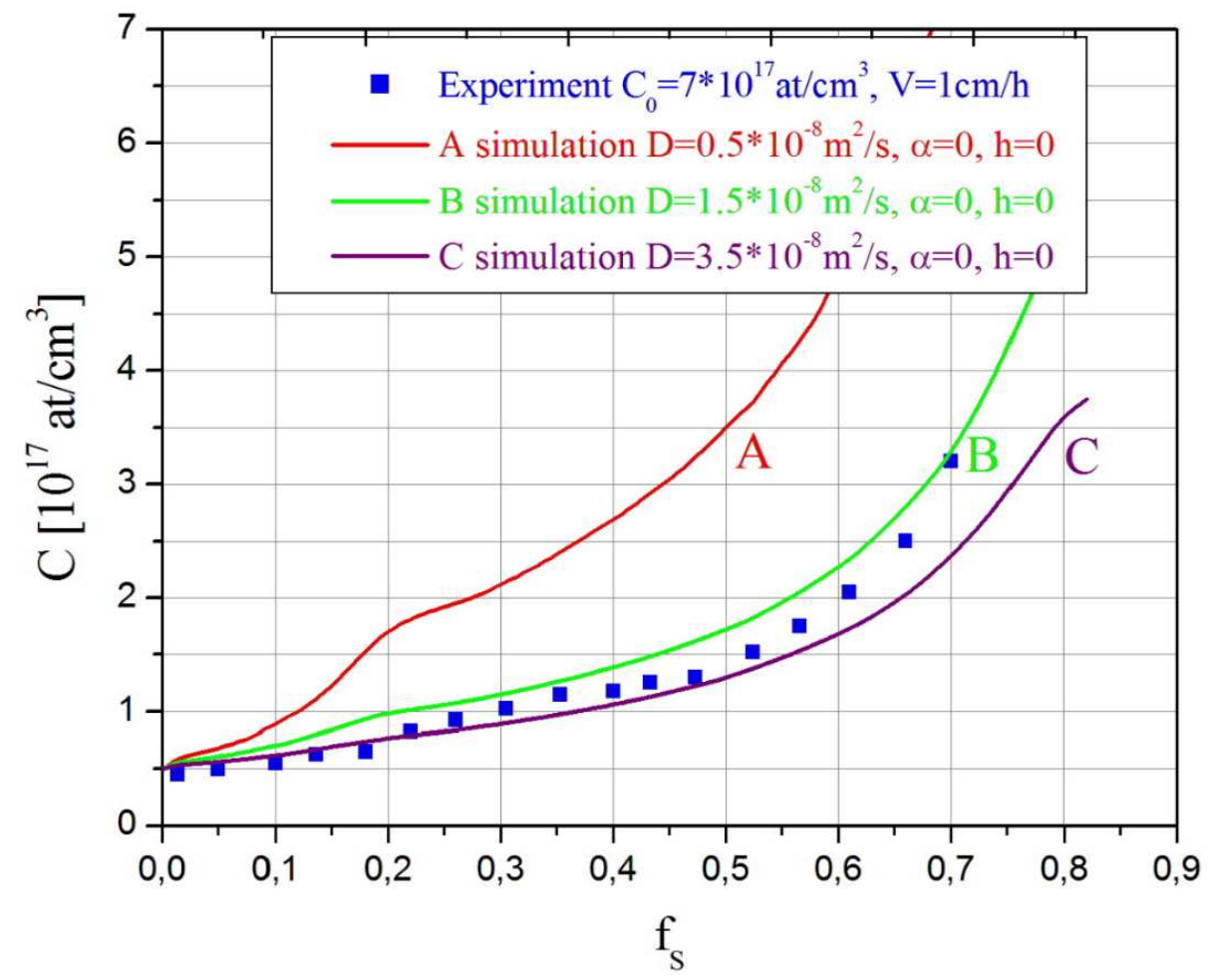

Fig. 4. Comparison of measured carbon distribution along the center axis (square symbols from [6]) to numerical results obtained with different values of the diffusion coefficient: $D=0.5 \cdot 10^{-8} \mathrm{~m}^{2} / \mathrm{s}$ (curve A), $D=1.5 \cdot 10^{-8} \mathrm{~m}^{2} / \mathrm{s} \quad\left(\right.$ curve B) and $D=3.5 \cdot 10^{-8} \mathrm{~m}^{2} / \mathrm{s}$ (curve C). Growth rate $V=$ $1 \mathrm{~cm} / \mathrm{h}$, initial concentration $C_{0}=7 \cdot 10^{17} \mathrm{at} / \mathrm{cm}^{3}$. 


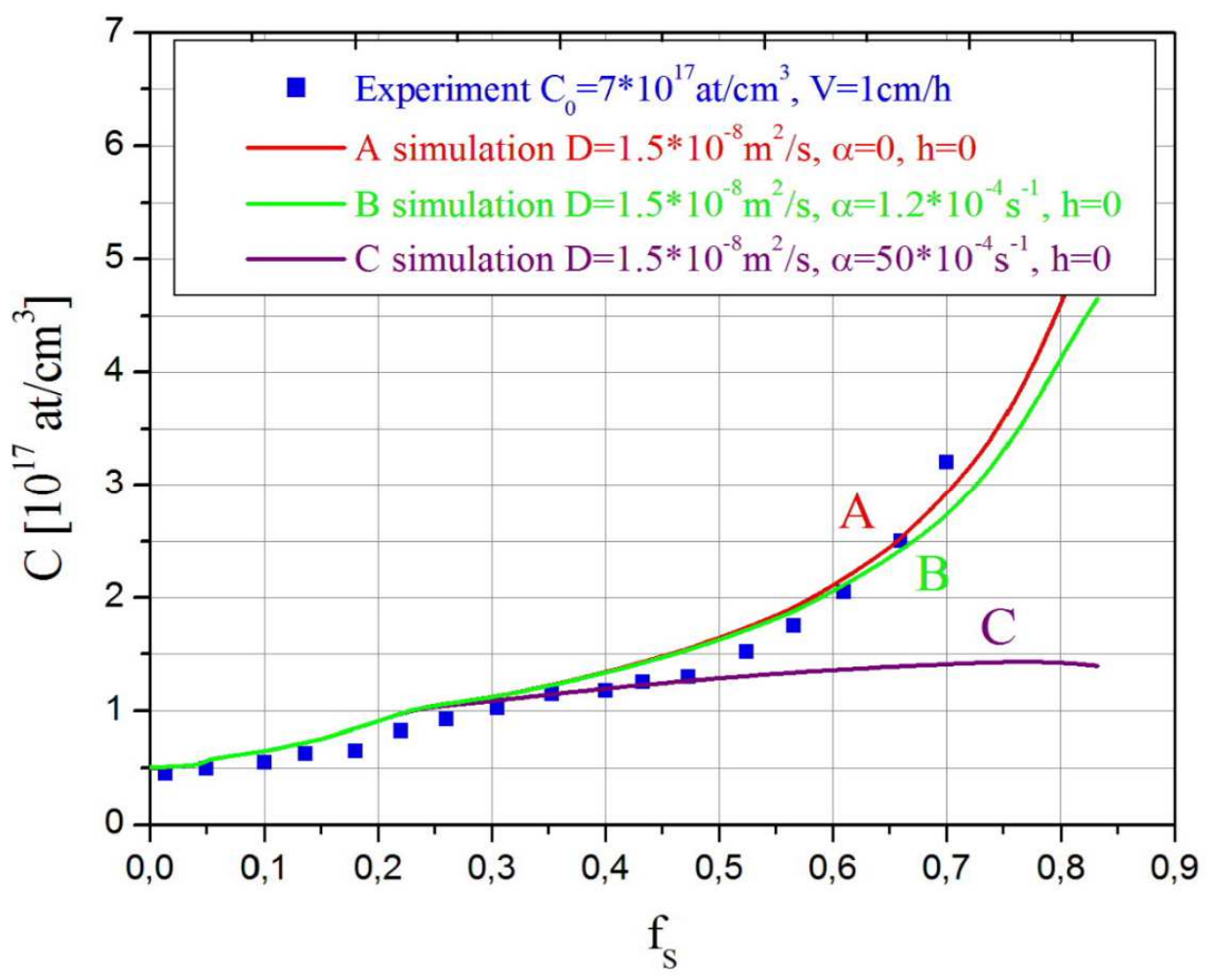

Fig. 5. Comparison of measured carbon distribution along the center axis (square symbols from [6]) to numerical results obtained with different values of the reaction rate coefficient: $\alpha=0$ (curve $\mathrm{A}$ ), $\alpha=$ $1.2 \cdot 10^{-4} \mathrm{~s}^{-1}$ (curve B) and $\alpha=50 \cdot 10^{-4} \mathrm{~s}^{-1}$ (curve C). Growth rate $V=1 \mathrm{~cm} / \mathrm{h}$, initial concentration $C_{0}=7 \cdot 10^{17} \mathrm{at} / \mathrm{cm}^{3}$, diffusion coefficient $D=1.5 \cdot 10^{-8} \mathrm{~m}^{2} / \mathrm{s}$. 


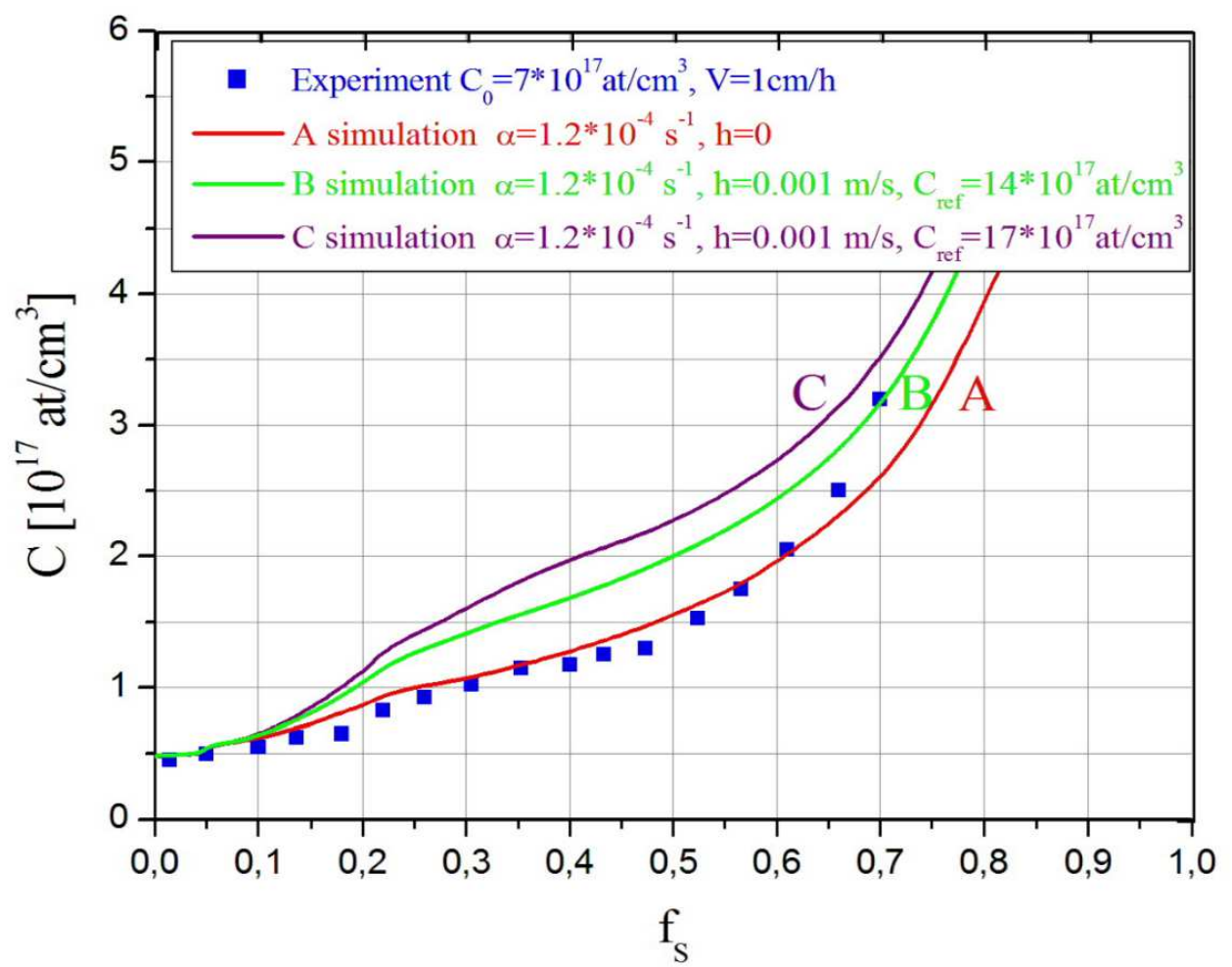

Fig. 6. Comparison of measured carbon distribution along the center axis (square symbols from [6]) to numerical results obtained with different values of the mass transfer coefficient and the reference concentration: $h=0$ (curve A), $h=0.001 \mathrm{~m} / \mathrm{s}$ and $C_{r e f}=14 \cdot 10^{17} \mathrm{at} / \mathrm{cm}^{3}$ (curve B), $h=$ $0.001 \mathrm{~m} / \mathrm{s}$ and $C_{\text {ref }}=17 \cdot 10^{17} \mathrm{at} / \mathrm{cm}^{3}$ (curve C). Growth rate $V=1 \mathrm{~cm} / \mathrm{h}$, initial concentration $C_{0}=7 \cdot 10^{17} \mathrm{at} / \mathrm{cm}^{3}$, diffusion coefficient $D=1.5 \cdot 10^{-8} \mathrm{~m}^{2} / \mathrm{s}$, reaction rate coefficient $\alpha=1.2$. $10^{-4} s^{-1}$ 


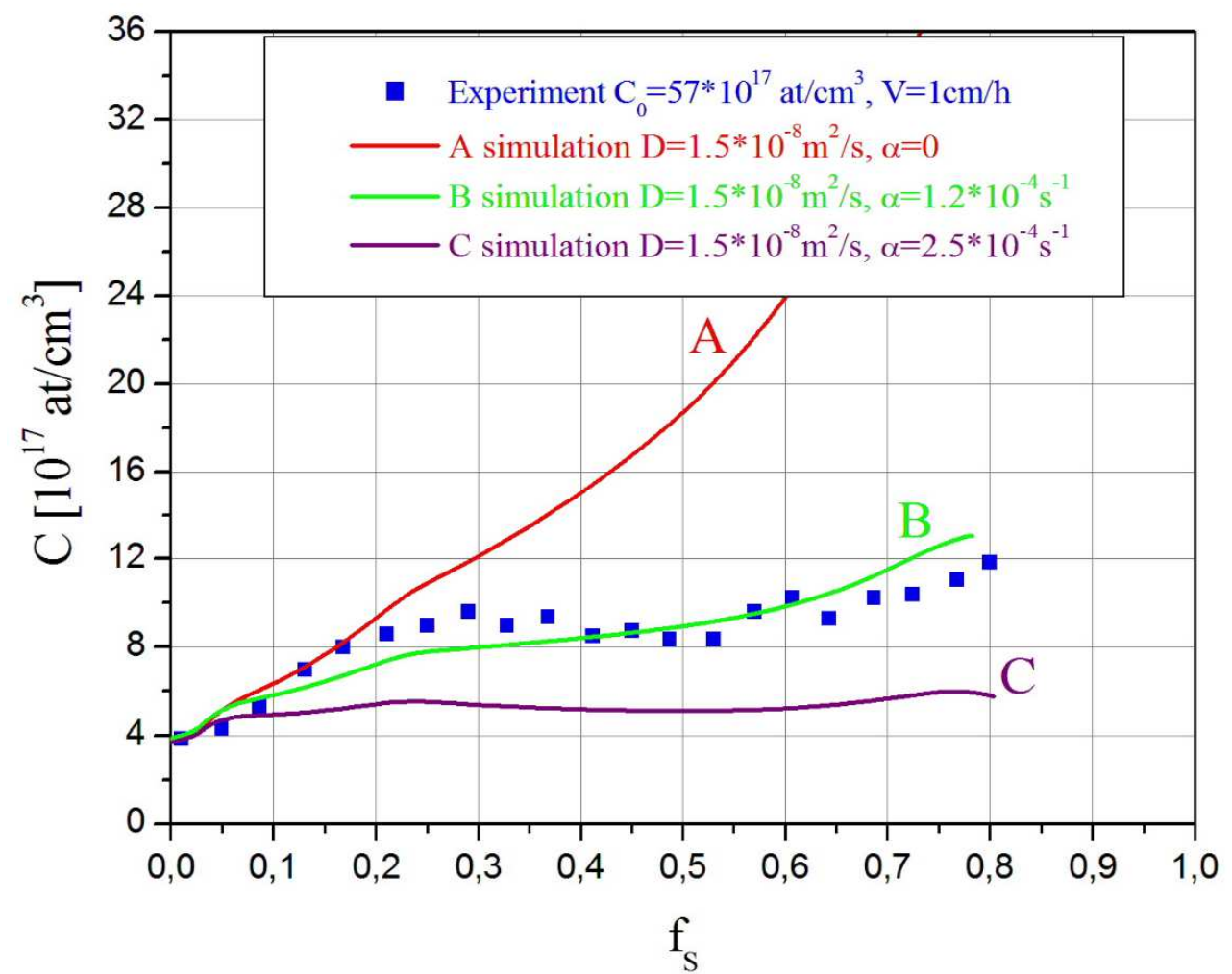

Fig. 7. Comparison of measured carbon distribution along the center axis (square symbols from [5]) to numerical results obtained with different values of the reaction rate coefficient: $\alpha=0$ (curve $\mathrm{A}$ ), $\alpha=$ $1.2 \cdot 10^{-4} \mathrm{~s}^{-1}$ (curve B) and $\alpha=2.5 \cdot 10^{-4} \mathrm{~s}^{-1}$ (curve C). Growth rate $V=1 \mathrm{~cm} / \mathrm{h}$, initial concentration $C_{0}=57 \cdot 10^{17} \mathrm{at} / \mathrm{cm}^{3}$, diffusion coefficient $D=1.5 \cdot 10^{-8} \mathrm{~m}^{2} / \mathrm{s}$. 


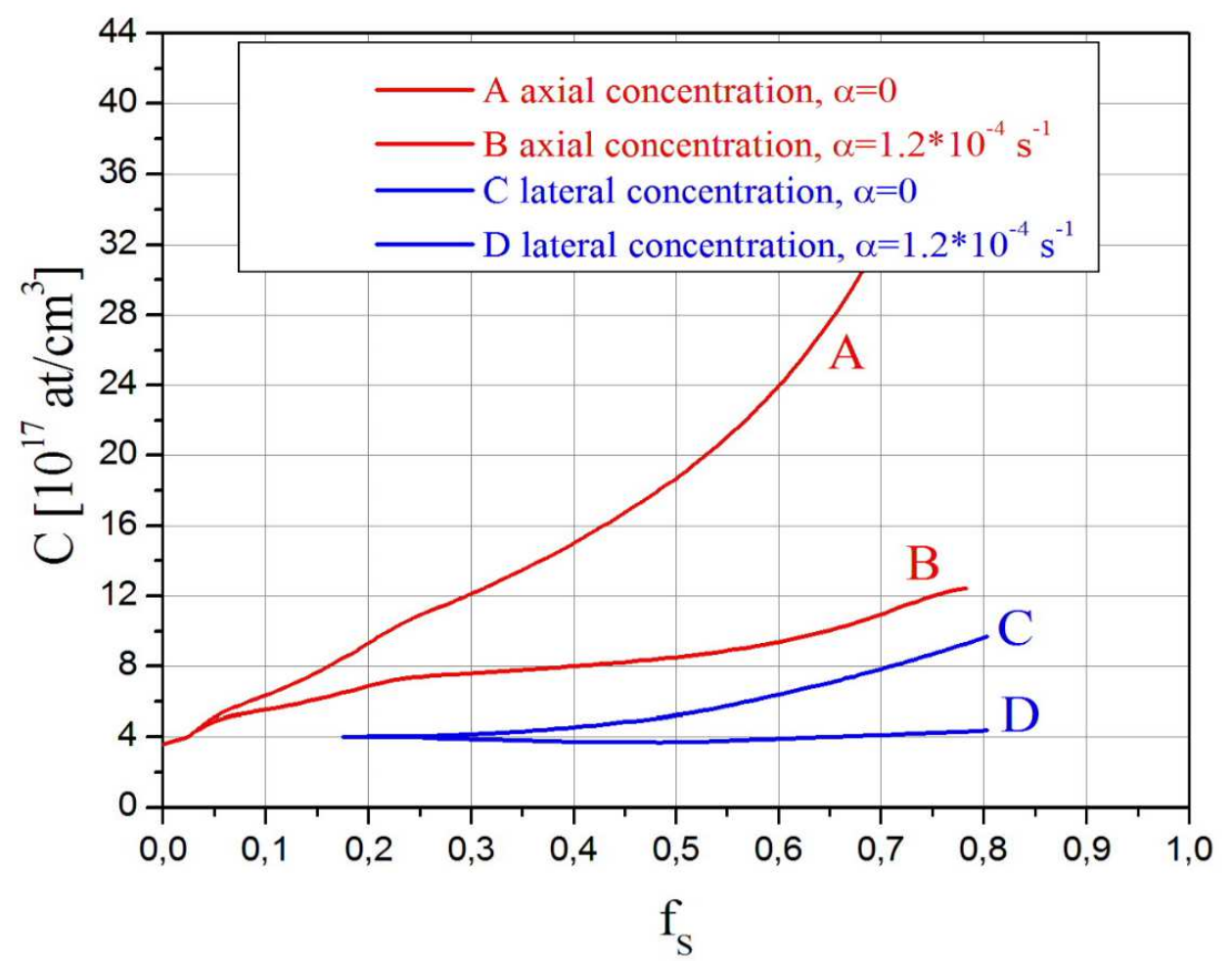

Fig. 8. Carbon distribution on the longitudinal direction: axial distribution for $\alpha=0$ (curve A) and $\alpha=1.2 \cdot 10^{-4} s^{-1}$ (curve B), lateral distribution for $\alpha=0$ (curve C) and $\alpha=1.2 \cdot 10^{-4} s^{-1}$ (curve D). Growth rate $V=1 \mathrm{~cm} / \mathrm{h}$, initial concentration $C_{0}=57 \cdot 10^{17} \mathrm{at} / \mathrm{cm}^{3}$, diffusion coefficient $D=$ $1.5 \cdot 10^{-8} \mathrm{~m}^{2} / \mathrm{s}$ 


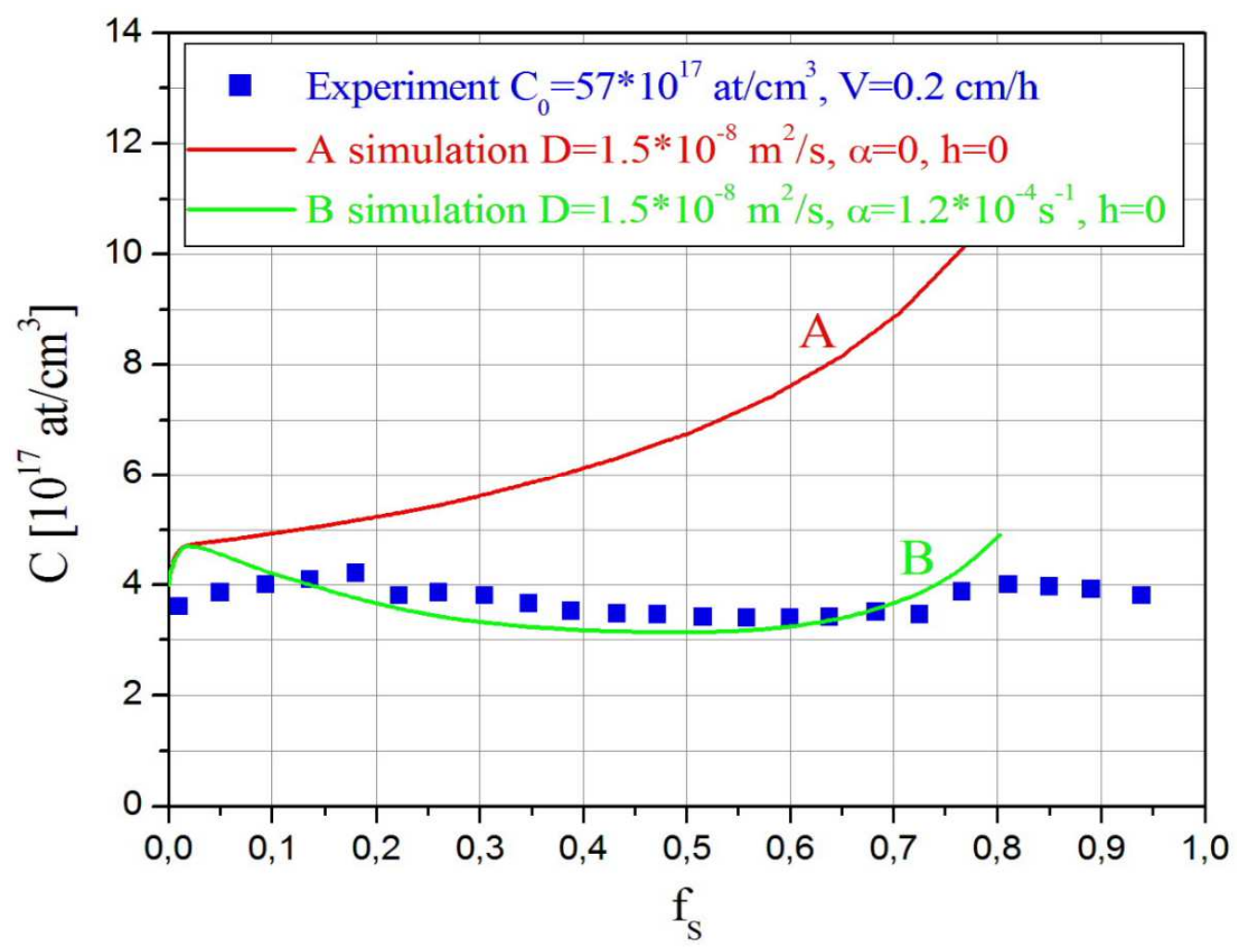

Fig. 9. Comparison of measured carbon distribution along the center axis (square symbols from [5]) to numerical results obtained for: $\alpha=0$ (curve A) and $\alpha=1.2 \cdot 10^{-4} s^{-1}$ (curve B). Growth rate $V=$ $0.2 \mathrm{~cm} / \mathrm{h}$, initial concentration $C_{0}=57 \cdot 10^{17} \mathrm{at} / \mathrm{cm}^{3}$, diffusion coefficient $D=1.5 \cdot 10^{-8} \mathrm{~m}^{2} / \mathrm{s}$. 